\title{
Flame Tube Testing of a GEA TAPS Injector: Effects of Fuel Staging on Combustor Fuel Spray Patterns, Flow Structure, and Speciation
}

Yolanda R. Hicks, Tyler G. Capil, and Robert C. Anderson

Glenn Research Center, Cleveland, Ohio 


\section{NASA STI Program . . . in Profile}

Since its founding, NASA has been dedicated to the advancement of aeronautics and space science. The NASA Scientific and Technical Information (STI) Program plays a key part in helping NASA maintain this important role.

The NASA STI Program operates under the auspices of the Agency Chief Information Officer. It collects, organizes, provides for archiving, and disseminates NASA's STI. The NASA STI Program provides access to the NASA Technical Report Server-Registered (NTRS Reg) and NASA Technical Report ServerPublic (NTRS) thus providing one of the largest collections of aeronautical and space science STI in the world. Results are published in both non-NASA channels and by NASA in the NASA STI Report Series, which includes the following report types:

- TECHNICAL PUBLICATION. Reports of completed research or a major significant phase of research that present the results of NASA programs and include extensive data or theoretical analysis. Includes compilations of significant scientific and technical data and information deemed to be of continuing reference value. NASA counter-part of peer-reviewed formal professional papers, but has less stringent limitations on manuscript length and extent of graphic presentations.

- TECHNICAL MEMORANDUM. Scientific and technical findings that are preliminary or of specialized interest, e.g., "quick-release" reports, working papers, and bibliographies that contain minimal annotation. Does not contain extensive analysis.
- CONTRACTOR REPORT. Scientific and technical findings by NASA-sponsored contractors and grantees.

- CONFERENCE PUBLICATION. Collected papers from scientific and technical conferences, symposia, seminars, or other meetings sponsored or co-sponsored by NASA.

- SPECIAL PUBLICATION. Scientific, technical, or historical information from NASA programs, projects, and missions, often concerned with subjects having substantial public interest.

- TECHNICAL TRANSLATION. Englishlanguage translations of foreign scientific and technical material pertinent to NASA's mission.

For more information about the NASA STI program, see the following:

- Access the NASA STI program home page at http://www.sti.nasa.gov

- E-mail your question to help@sti.nasa.gov

- $\quad$ Fax your question to the NASA STI Information Desk at 757-864-6500

- Telephone the NASA STI Information Desk at 757-864-9658

- Write to:

NASA STI Program

Mail Stop 148

NASA Langley Research Center Hampton, VA 23681-2199 
Flame Tube Testing of a GEA TAPS Injector: Effects of Fuel Staging on Combustor Fuel Spray Patterns, Flow Structure, and Speciation

Yolanda R. Hicks, Tyler G. Capil, and Robert C. Anderson Glenn Research Center, Cleveland, Ohio

Prepared for the 2018 Joint Propulsion Conference cosponsored by the AIAA, SAE, and ASEE Cincinnati, Ohio, July 9-11, 2018

National Aeronautics and Space Administration

Glenn Research Center Cleveland, Ohio 44135 


\section{Acknowledgments}

This work was supported by the NASA Aeronautics Research Mission Directorate. We acknowledge our industry partners at GE Aviation.

This report contains preliminary findings, subject to revision as analysis proceeds.

Trade names and trademarks are used in this report for identification only. Their usage does not constitute an official endorsement, either expressed or implied, by the National Aeronautics and Space Administration.

Level of Review: This material has been technically reviewed by technical management.

Available from

NASA STI Program

Mail Stop 148

NASA Langley Research Center

Hampton, VA 23681-2199
National Technical Information Service 5285 Port Royal Road Springfield, VA 22161 703-605-6000

This report is available in electronic form at http://www.sti.nasa.gov/ and http://ntrs.nasa.gov/ 


\title{
Flame Tube Testing of a GEA TAPS Injector: Effects of Fuel Staging on Combustor Fuel Spray Patterns, Flow Structure, and Speciation
}

\author{
Yolanda R. Hicks, Tyler G. Capil, and Robert C. Anderson \\ National Aeronautics and Space Administration \\ Glenn Research Center \\ Cleveland, Ohio 44135
}

\begin{abstract}
This paper presents results in which we compare fuel staging and its effect on fuel spray pattern, velocity and speciation during combustion for several inlet conditions using a GE TAPS injector configuration. Planar laser-induced fluorescence (PLIF), particle image velocimetry (PIV) and phase Doppler interferometry (PDI) were used to investigate spray patterns and velocity. The 2D PIV provides slices in the flow of axial-vertical or axial-horizontal velocity components. With 3D PDI, we obtained three components of velocity, and fuel drop sizes. Chemiluminescence imaging and spontaneous Raman scattering (SRS) were used to investigate flame structure, species location and relative species concentration. Phase Doppler and PIV data were acquired using scatter from fuel droplets; therefore, those data were obtained only at the pilot-only test points. Raman measurements were acquired only at $10 / 90 \mathrm{pilot} / \mathrm{main}$ split points to avoid droplets.
\end{abstract}

\section{Nomenclature}

AST Advanced Subsonic Technology

CRZ central recirculation zone

D10 linear droplet diameter

EINOX emission index for oxides of nitrogen

ERA Environmentally Responsible Aviation

FAR fuel-to-air ratio

FWHM full width at half maximum

GRC Glenn Research Center

LTO landing-takeoff cycle

NOx nitrogen oxides, oxides of nitrogen

$\mathrm{P}_{3} \quad$ combustor inlet pressure

PDI phase Doppler interferometry

PIV particle image velocimetry

PLIF planar laser-induced fluorescence

PLS planar laser scatter

RMS Root-Mean-Square

SLTO sea level takeoff

SRS spontaneous Raman scattering

TAPS twin annular premixing swirler

$\mathrm{T}_{3} \quad$ combustor inlet temperature

UV ultraviolet 


\section{Introduction}

Emissions of oxides of nitrogen (NOx) have long been a concern in the aviation industry because NOx contributes to smog at lower altitudes and may negatively affect the protective ozone layer at high altitude (Ref. 1). The aviation industry is also continuously trying to lower fuel burn. Lowering fuel burn is achieved through gains in thermodynamic efficiency and also has benefits, both economic and environmental. Efficiency gains may be achieved by increasing the engine operating pressure ratio, which increases combustor inlet temperature; however, NOx formation rates increase with higher temperatures. Without an improvement in combustor technology, higher efficiency engines will have higher, not lower, NOx emissions: improved low-NOx combustor technologies need to be developed.

General Electric Aviation (GE) explored the Twin Annular Premixing Swirler (TAPS) injector concept (Figure 1, Ref. 2) in the mid-1990s, and proposed TAPS as its primary approach to achieve NASA's Advanced Subsonics Technology (AST) initiative to reduce NOx emissions below 60 percent of the 1996 ICAO standards, while maintaining low CO emissions. Over the years, NASA has tested selected TAPS research hardware in GRC combustor facilities, during contractual collaborations under AST, the Ultra Efficient Engine Technology (UEET), Fundamental Aeronautics, and Environmentally Responsible Aviation Programs (Refs. 3 and 4).

In this paper, we revisit flame tube testing of one research TAPS injector. Specifically, the primary objective for this study was to compare fuel staging and its effects on fuel spray pattern, velocity and fuel droplet sizes, and speciation during combustion. The comparison was enabled through the use of several optical and laser-based measurement techniques. Planar laser induced fluorescence of $\mathrm{OH}$ was used to emphasize fuel spray patterns as well as locations of the primary reaction zone. Chemiluminescence imaging enabled qualitative visualization of key excited, nascent species of combustion including $\mathrm{CH}^{*}$, $\mathrm{C}_{2}{ }^{*}, \mathrm{OH}^{*}$, and $\mathrm{NO}^{*}$. 2D particle image velocimetry measured axial and cross-flow velocities which were used to characterize the TAPS injector's flow field performance in regards to fuel spray. Additional measurements from phase Doppler interferometry also provided three-component velocity measurements as well as fuel droplet sizes. Spontaneous Raman spectroscopy was implemented in these tests to examine speciation and temperature.

In the following, we briefly describe the TAPS hardware, the experimental setup and test matrix. This is followed by a description of the optical diagnostics used. The results and discussion section presents PLIF results, velocity and droplet size results, chemiluminescence imaging results, and results from spontaneous Raman scattering diagnostics.

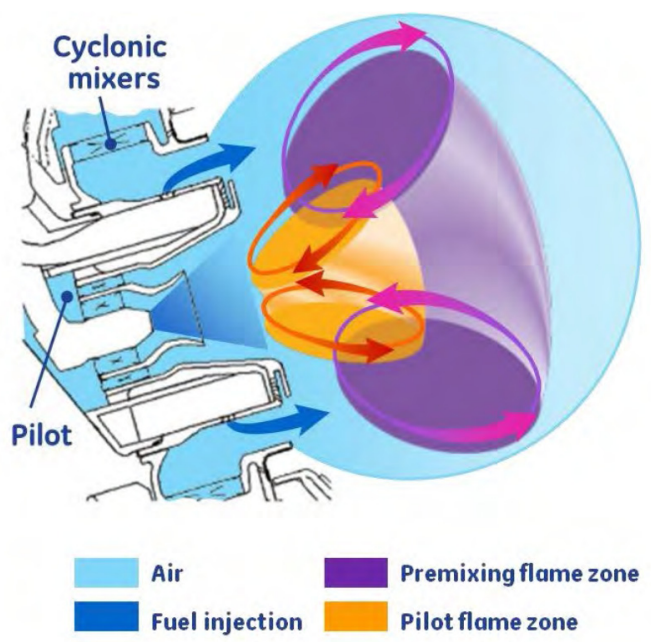

Figure 1.-TAPS injection concept (Ref. 6). 


\section{TAPS Hardware}

The TAPS injector concept, illustrated in Figure 1 and described in References 2, 5 and 6, consists of a pilot stage and a main stage, with turndown controlled by shifting the fuel distribution between the stages. As seen in this TAPS concept sketch, the pilot fuel circuit injects a conical spray from the center of the cup. When running in pilot-only mode, this zone is locally fuel-rich for added stability. The main fuel circuit feeds a number of discrete jets-in-crossflow into the surrounding annular passage as a means to promote fuel breakup, vaporization and some premixing with the incoming air before exiting the dome. Swirl is imparted to the air that flows through each circuit.

\section{Experiment Setup}

\section{TAPS Installation}

The combustor subcomponent test facility at NASA Glenn supplies heated, nonvitiated air to the test rig. The test rig uses a castable ceramic to form the combustor "liner". A single TAPS cup was installed in the rig using a cylindrical cast liner, with cutouts for optical access. The TAPS injector was installed such that the optics could probe the region immediately downstream of the dump plane in the mixing region between the pilot and main circuits.

\section{Test Matrix}

The primary inlet conditions used are shown in Table 1. The specific inlet conditions are not from any particular engine size class or cycle, but we normalized the fuel/air ratio (FAR) based on a large engine Generation-2 ERA cycle. Temperatures and pressures are de-rated from higher power conditions due to facility limitations. Four fuel splits were run between pilot and main: 100, 60, 20, and 10 percent pilot. For selected points, we also ran high-low cases for fuel/air ratio.

\section{Optical Diagnostics Setup and Procedures}

Five techniques were used to examine the TAPS injector flow field immediately downstream of the dome dump plane, in a region between the pilot and main circuits. Planar laser-induced fluorescence (PLIF) of fuel and $\mathrm{OH}$ was used to determine fuel spray patternation and image the reaction zone. Chemiluminescence imaging of radical combustion species $\mathrm{C}_{2}{ }^{*}, \mathrm{CH}^{*}, \mathrm{OH}^{*}$, and $\mathrm{NO}^{*}$ (with emissions at 515-nm, 427-nm, 306-nm, 237-nm) was also used for reaction zone flame structure. 2D planar image velocimetry (PIV) was used to determine the axial and cross-flow velocities, particularly of the fuel spray. Phase Doppler interferometry (PDI) was used to measure fuel droplet velocities and sizes. Spontaneous Raman scattering (SRS) was used to measure combustion species and temperature.

PLIF and chemiluminescence images were acquired for all conditions shown in the test matrix. Because we relied on droplets for the velocity measurements, PIV and PDI data were acquired only at the pilot only (100/0) split conditions, which also had the lowest $\mathrm{T}_{3}$ and $\mathrm{P}_{3}$. For SRS, we wanted to avoid droplets, so data were obtained only at 10/90 split conditions.

TABLE 1.-PRIMARY CONDITIONS USED FOR TAPS FUEL INJECTION TESTS

\begin{tabular}{|c|c|c|c|c|}
\hline $\begin{array}{c}\text { Test } \\
\text { point }\end{array}$ & $\begin{array}{c}\mathrm{P}_{3} \\
\text { psia }\end{array}$ & $\begin{array}{c}\mathrm{T}_{3} \\
{ }^{\circ} \mathrm{F}\end{array}$ & $\begin{array}{c}\text { Fuel split } \\
\% \text { Pilot/Main }\end{array}$ & FAR/FARsLTo \\
\hline 1 & 166 & 650 & $100 / 0$ & 0.54 \\
\hline 2 & 135 & 720 & $100 / 0$ & 0.70 \\
\hline 3 & 200 & 925 & $60 / 40$ & 0.71 \\
\hline 4 & 250 & 1000 & $20 / 80$ & 0.84 \\
\hline 5 & 250 & 1000 & $10 / 90$ & 0.74 \\
\hline 6 & 150 & 1000 & $10 / 90$ & 0.74 \\
\hline
\end{tabular}


All speciation images (PLIF and chemiluminescence) we obtained using intensified CCD (ICCD) camera having a Gen II Super Blue, Slow gate intensifier. The gate time used was 50-ns. For PLIF, the laser was a $10-\mathrm{Hz}$, frequency-doubled Nd:YAG-pumped dye laser/frequency mixer system set to produce wavelengths around 282-nm. A laser was not used for chemiluminescence images.

Chemiluminescence imaging has become increasingly popular as a simple way to visualize the reaction zone via $\mathrm{OH}^{*}, \mathrm{CH}^{*}$, and $\mathrm{C}_{2} *$ (Refs. 7 to 10). Chemiluminescence has been used to determine reaction rates and zone thicknesses, primarily in premixed methane/air flames. There have also been studies to quantify imaging of these species, which involves measuring and accounting for the broad signal from $\mathrm{CO}_{2} *$ that overlaps these species (Refs. 9 and 10). Guiberti et al. (Ref. 10) determined that while $\mathrm{CO}_{2} *$ interference with $\mathrm{CH}^{*}$ was significant, interference with $\mathrm{OH}^{*}$ was not. The chemiluminescence images presented here are not corrected for any spectral interferences and should be considered qualitative.

When obtaining OH PLIF, we typically get relatively strong background interference near the dome because refined JP-class fuels have up to 25 percent aromatics by volume; certain of these aromatics, such as methyl-benzenes and naphthalenes, are broadband absorbers and emitters in the same wavelength region we use to excite $\mathrm{OH}$ (Refs. 11 to 14). Therefore, to obtain OH PLIF, we collected raw fluorescence signal when tuned to the $\mathrm{R}_{1} 1$ line in the $\mathrm{A}^{2} \Sigma^{+} \leftarrow \mathrm{X}^{2} \Pi(1,0)$ band and collected light from the $(1,1)$ band using a filter centered near 313-nm. We then tuned off the excitation line to collect background light from the fuel. We designated this fuel fluorescence Fuel-313. Fuel-313 is subtracted from the raw OH PLIF signal to render OH PLIF images. Because the peak fuel fluorescence is near 330-nm, we also obtained fuel PLIF using a filter centered at 334-nm and designate that fuel PLIF as fuel-334. The two sets of fuel PLIF were obtained at the same time using cameras on opposite sides of the combustor.

The Raman setup was used to explore the Stokes/Anti-Stokes method for deriving combustion temperature. As such, the spectrometer grating was chosen to obtain both nitrogen peaks, at $2331 \mathrm{~cm}^{-1}$ from the laser line. We think this method has potential, but the small inlet temperature range available limited our ability to calibrate the system as we would like. Speciation was still possible, even though the spectral range restricted the region of species available to that between $\mathrm{CO}_{2}$ and $\mathrm{N}_{2}$.

\section{Specific Setup Details}

Using a setup similar to that shown in Figure 2(a) (one camera on either side, with light collected from an angle perpendicular to the combustor flow direction) we acquired two-dimensional images of $\mathrm{OH}$ and fuel PLIF, and chemiluminescence images of $\mathrm{C}_{2}{ }^{*}, \mathrm{CH}^{*}, \mathrm{OH}^{*}$, and $\mathrm{NO}^{*}$.

The OH PLIF, fuel-313 PLIF, $\mathrm{CH}^{*}, \mathrm{OH}^{*}$, and $\mathrm{NO}^{*}$ images were obtained using the same receiving optics and intensified ICCD camera. The second ICCD camera was used to record fuel-334 PLIF and $\mathrm{C}_{2} *$. Remotely controlled filter wheels allowed us to select a species-specific filter (FWHM of 10-nm, typical) to pass light through a UV-grade, $\mathrm{f}=105-\mathrm{mm}, \mathrm{f} / 4.5$, macro camera lens. The light was then focused onto a gated, 16-bit, $1 \mathrm{k} \times 1 \mathrm{k}$ pixel array, ICCD camera (Princeton Instruments PIMAX) having a Gen II SuperBlue-Slow-Gate intensifier. The laser beam was formed into a sheet using a pair of cylindrical lenses, to obtain a sheet approximately $300-\mu \mathrm{m}$ thick. We typically acquired images with on-chip averages of 200 gates, and traversed across the flow along the $\mathrm{Y}$ axis in 1-mm increments. The laser sheet and collection optics were traversed together so as to maintain focus on the laser sheet. For chemiluminescence, we did not use the laser and collected light with the camera focused on a plane at $\mathrm{Y}=0$ (coincident with the injector centerline) using species-specific filters centered at 514-nm, 432-nm, 313-nm, and 237-nm for $\mathrm{C}_{2}{ }^{*}, \mathrm{CH}^{*}, \mathrm{OH}^{*}$, and $\mathrm{NO}^{*}$, respectively.

The 2D PIV images were also acquired using a setup similar to Figure 2(a). The laser used was a dual head, frequency-doubled Nd:YAG laser operating at 15-Hz. The camera was a frame transfer CCD with $1200 \times 1600$ pixel resolution. As with PLIF, the laser sheet and camera were traversed across the flow, in 1-mm increments. We also used an alternate setup, with the camera positioned above the combustor and inserted a horizontal laser sheet through the side window. We collected 500 image pairs to produce instantaneous vector fields as well as an average $2 \mathrm{D}$ vector field. 
(a)

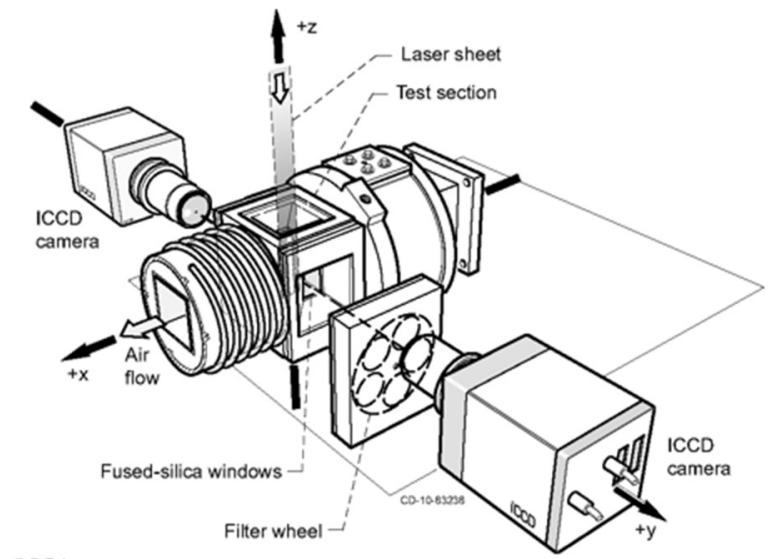

(b)

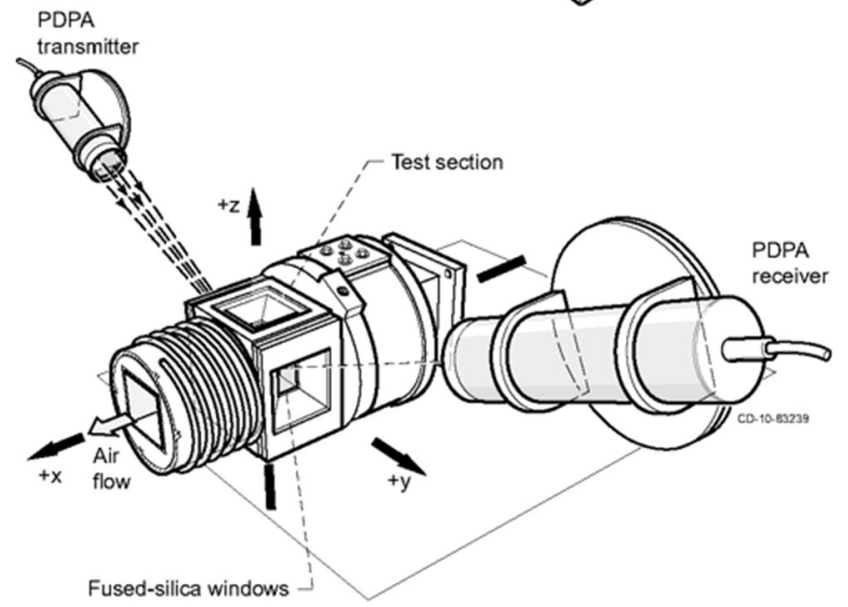

(c)

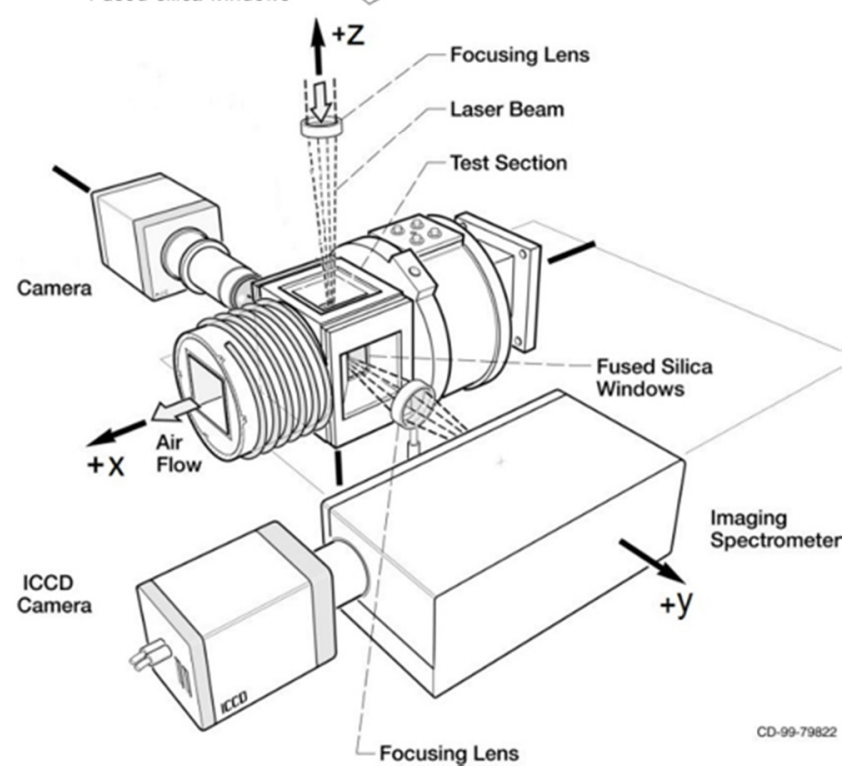

Figure 2.-Schematic drawings that shows typical components and configuration used for 2D imaging methods: (a) planar laser-induced fluorescence, PIV, and chemiluminescence; (b) Phase Doppler Interferometry; (c) Raman spectroscopy. 
Phase Doppler data were acquired using a setup similar to the schematic shown in Figure 2(b), which shows the transmitter and receiver angled downward in order to access the area more directly downstream from the TAPS pilot region. The transmitter-receiver were set up in $30^{\circ}$ forward scatter arrangement, each at $15^{\circ}$ with respect to the horizontal. Three nonorthogonal components were obtained using a three-color system via a single transmitter, so two geometric transforms were applied to the collected raw signalone for the optical system, the other because of the $15^{\circ}$ tilt - so that the velocity vectors conformed to the convention we used for the combustion system. The available optical access limited the traverse range in the axial direction to approximately 12-mm.

Raman spectra were acquired using a setup shown in the schematic from Figure 2(c). A 30-Hz frequency doubled Nd:YAG laser beam was focused on a point in the flow path. The Raman signal was captured by a $60-\mathrm{mm}, \mathrm{f} / 2.8$, micro-Nikkor lens coupled to a fiber optic. The fiber optic was then coupled to the spectrometer and imaged onto an Andor iStar 734, intensified CCD camera. The spectrometer used a 300 -groove $/ \mathrm{mm}$ grating blazed at $500-\mathrm{nm}$. The fiber optic consisted of 37 fibers which were aligned vertically along the z-coordinate. Furthermore, the 37 fibers were binned together to form 10 strips on the ICCD array. For the results presented here, spectra were collected with 2000 laser shots for on-chip averages. Raman scattering was collected along the x-coordinate, typically traversing from $-15 \mathrm{~mm}$ to $15 \mathrm{~mm}$ in $5 \mathrm{~mm}$ increments. Overall, this provides a total spatial region that spans $30 \mathrm{~mm}$ in the $\mathrm{x}$-direction, and about $4 \mathrm{~mm}$ in the z-direction. The Raman data presented in this paper was limited to the $10 / 90$ fuel split conditions.

\section{Results and Discussion}

In this section, we present results from chemiluminescence and the laser-based techniques, PLIF, SRS, PIV and PDI. For these results, images are plotted either as side views, with flow from left to right; or as end views, from an aft looking forward perspective. In either case, the vertical axis plots the relative distance from the TAPS centerline. Keep in mind the field-of-view is the region immediately downstream of the dome. The probe volume visible through the windows allows us to observe the intersection of the pilot and pre-mixing flame zones.

\section{PLIF Results}

Figure 3 shows results obtained for a pilot-only case (fuel split 100/0), test point 1 . As we describe the results for this inlet condition, we also use this point to discuss some pros and cons for this implementation of the PLIF measurement and the combusting system. Figure 3(a) and (b) show color contours of OH PLIF. Figure 3(a) is a side view at $\mathrm{Y}=0$ with flow from left to right. Figure 3(b) shows an end view composite slice at one axial position, with flow out of the page. The image in Figure 3(c) is the composite background signal when the laser is tuned away from the $\mathrm{OH}$ excitation line, captured using the same optical filtering as when the laser is tuned to the excitation line; the $\mathrm{OH}$ images presented represent this off-line signal subtracted from the on-line signal. The image in Figure 3(d) was acquired using a different camera on the opposite side of the combustor. This image was acquired at the same time as the background OH PLIF (fuel-313), but using a filter centered at 334-nm, which is closer to the peak of fuel fluorescence and spectrally not near $\mathrm{OH}$ fluorescence.

With respect to the end views, the camera used to acquire the $\mathrm{OH}$ and background fuel PLIF images was on the right (Figure 3(d)) and the fuel only camera was on the left (Figure 3(c)). The combusting system is optically thick so that the fluorescence signal is considerably weaker on the side away from the camera. Evidence of this thickness is most apparent in the pilot-only cases, which have a higher local number density than the conditions with fuel splits. Given that we were looking at relative trends, we did not attempt to correct for multiple scattering and absorption of the laser.

In comparing the two optical filtering techniques for fuel PLIF (Figure 3(c) and (d), for example), we determined that the two methods gave us identical information, but we had stronger signal using the 334-nm filter, so all remaining fuel PLIF images are of fuel-334. 


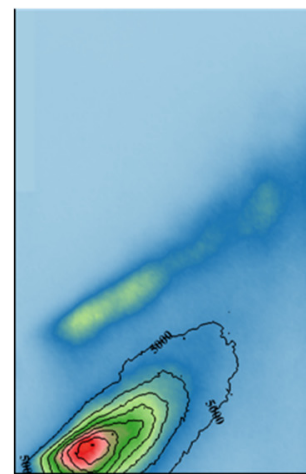

(a)

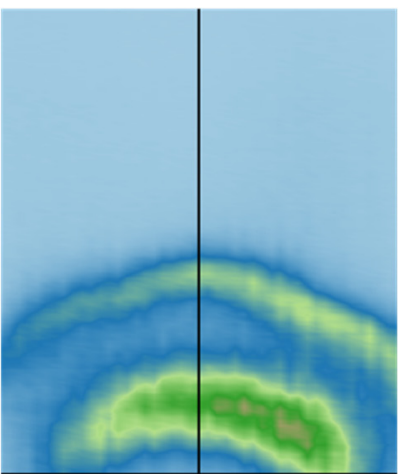

(b)

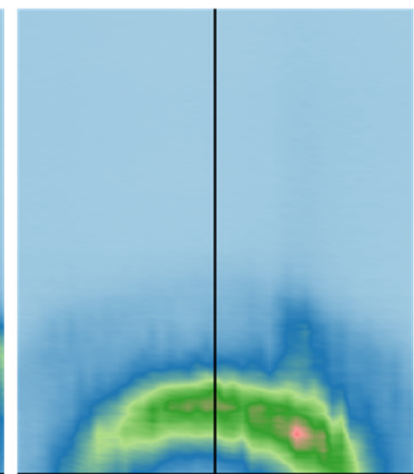

(c)

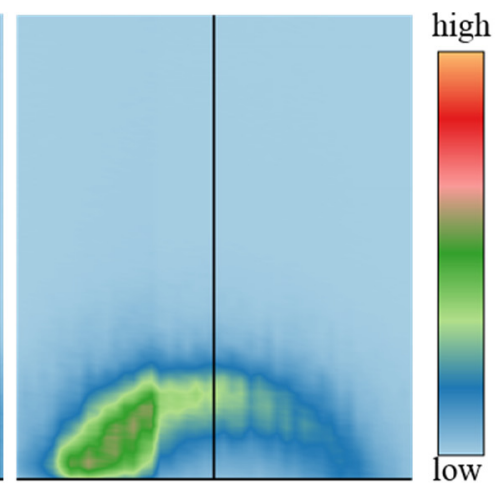

(d)

Figure 3.-PLIF Results obtained for a pilot-only case (fuel split 100/0), test point 1. (a) OH PLIF side view at $Y=0$,

(b) OH PLIF composite end view slice, (c) composite end view background with laser tuned away from OH (fuel-313),

(d) fuel-334 PLIF with filter centered at $334 \mathrm{~nm}$. Line contours in (a) denote location of fuel-313 PLIF signal for comparison with OH PLIF.

In Figure 3(a), the fuel PLIF images show an annular ring of fuel that is relatively uniform in distribution within the annulus and symmetric about the center position. The OH PLIF images show two zones of $\mathrm{OH}$ : a region of high signal emanating from the pilot spray, and a region where $\mathrm{OH}$ forms on the fuel-lean side of the spray in the shear layer mixing region. In the current study, the contours of fuel PLIF and OH PLIF lie on top of each other. In previous work when comparing the locations of fuel and $\mathrm{OH}$, we generally saw a shift in $\mathrm{OH}$ to the inside of fuel spray cone, but the shift in the $\mathrm{OH}$ signal with respect to fuel near the dome in this case is very slight or not present. It may also be the case that the field of view prevents our seeing any portion of the interior of the pilot zone. The contour lines in Figure 3(a) show the fuel position relative to the color contour of OH PLIF. Figure 3(a) also shows that the fuel PLIF signal does not extend far downstream before it is converted to smaller species or consumed. For the pilot-only conditions, the fuel signal dissipates within about $25-\mathrm{mm}$ from the dump plane. That distance is shorter for conditions that also have the main fuel circuit active.

Figure 4 shows fuel PLIF (top row) and OH PLIF for the 60/40 fuel split condition. The left column shows the side view and the second and third columns show end views at two axial locations. The fuel PLIF shows a uniformly-distributed pilot region but very distinct regions of stronger fuel signal from the main injector. The $\mathrm{OH}$ side view image indicates a bimodal axial distribution and shows most of the signal on the outside of the fuel PLIF location. We saw a similar pattern in the $\mathrm{OH}^{*}$ chemiluminescence signal for this condition (see Figure 7). Also there is evidence of optical thickness, since the right-hand (OH camera) side of the end views shows a fairly uniform $\mathrm{OH}$ distribution in the region between the pilot and main fuel circuits while the left-hand side does not.

Figure 5 and Figure 6 present end view composites of fuel and $\mathrm{OH}$ acquired at $\mathrm{P}_{3}$ of 250-psia, and with axial position increasing from left to right in each row. Each column is nominally at the same axial position, beginning at the dome. Because good fuel signal does not extend as far downstream as the $\mathrm{OH}$ signal since the fuel is consumed in the combustion process, we limit the fuel PLIF images to within the first $10 \mathrm{~mm}$ from the dump plane.

In both Figure 5 and Figure 6, the top row is from the 20/80 fuel split condition. The next two rows show the 10/90 split conditions with equivalence ratios 10 percent below and above that for the 20/80 split condition. Fuel patternation is similar in all three cases. Fuel (Figure 5) from the pilot region is barely perceptible and, although there is still separation between the individual main circuit injection sites, the overall fuel distribution is more uniform than we observed for the $60 / 40$ fuel split condition shown in Figure 4. Other differences are observed when looking at $\mathrm{OH}$ distribution (Figure 6) compared to the $60 / 40$ split, particularly farther downstream. The $20 / 80$ split shows a more uniform distribution, whereas for the 10/90 split, relatively little $\mathrm{OH}$ is produced within the inner part of the cone, in the lower part of the images. 

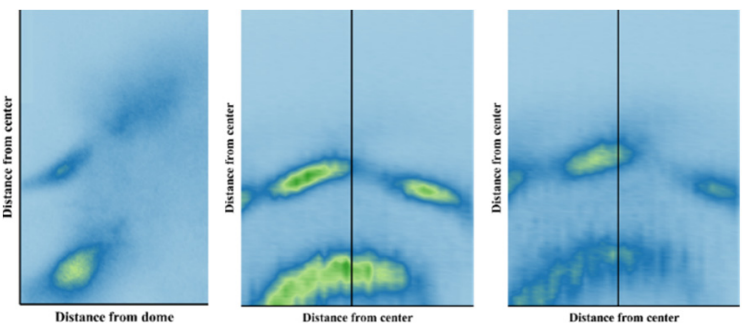

Fuel PLIF
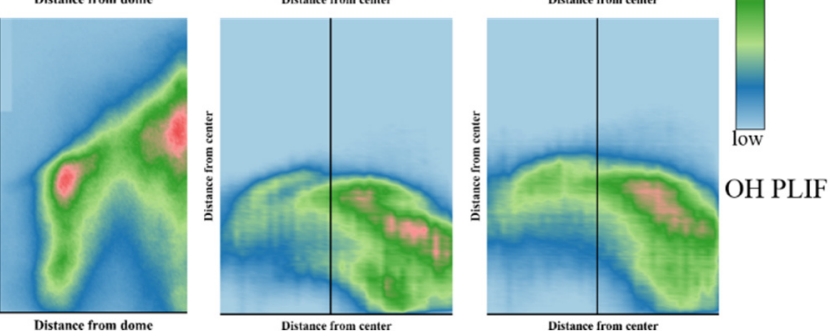

Figure 4.-PLIF Results obtained for a the 60/40 fuel split, test point 3. Top row: fuel-334, bottom row: $\mathrm{OH}$. The first column shows the side view at $Y=0$, the second and third columns show composite end views at two axial locations.
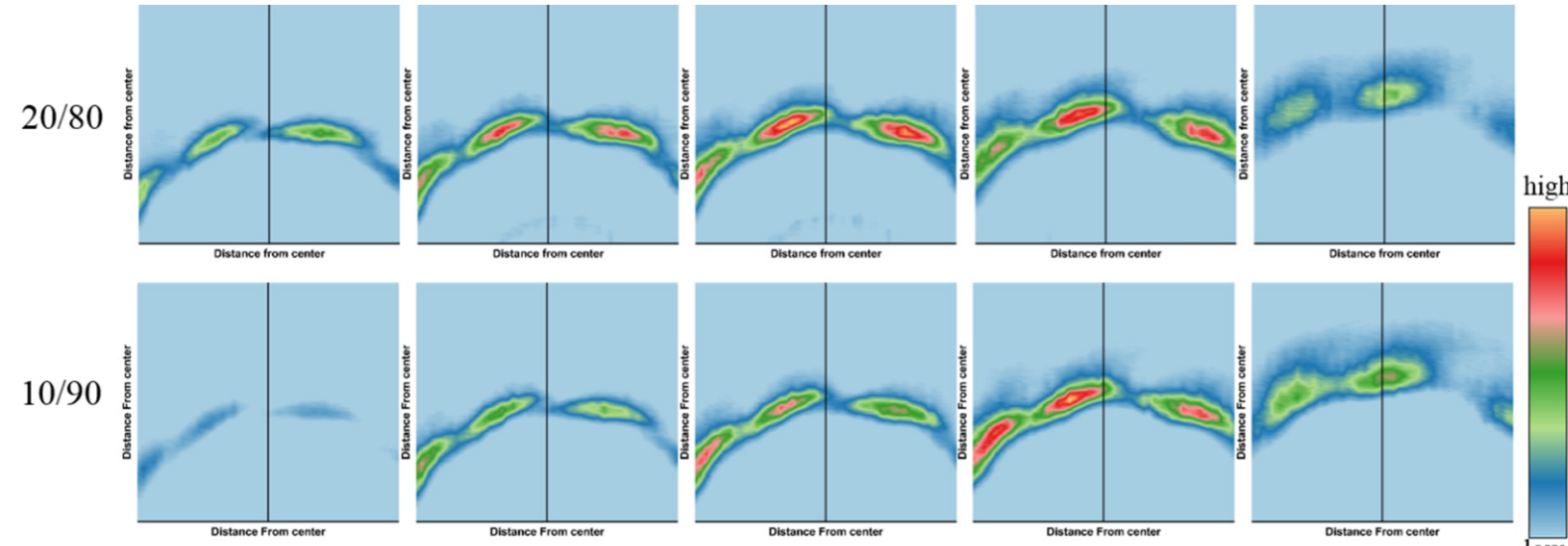

$10 / 90$
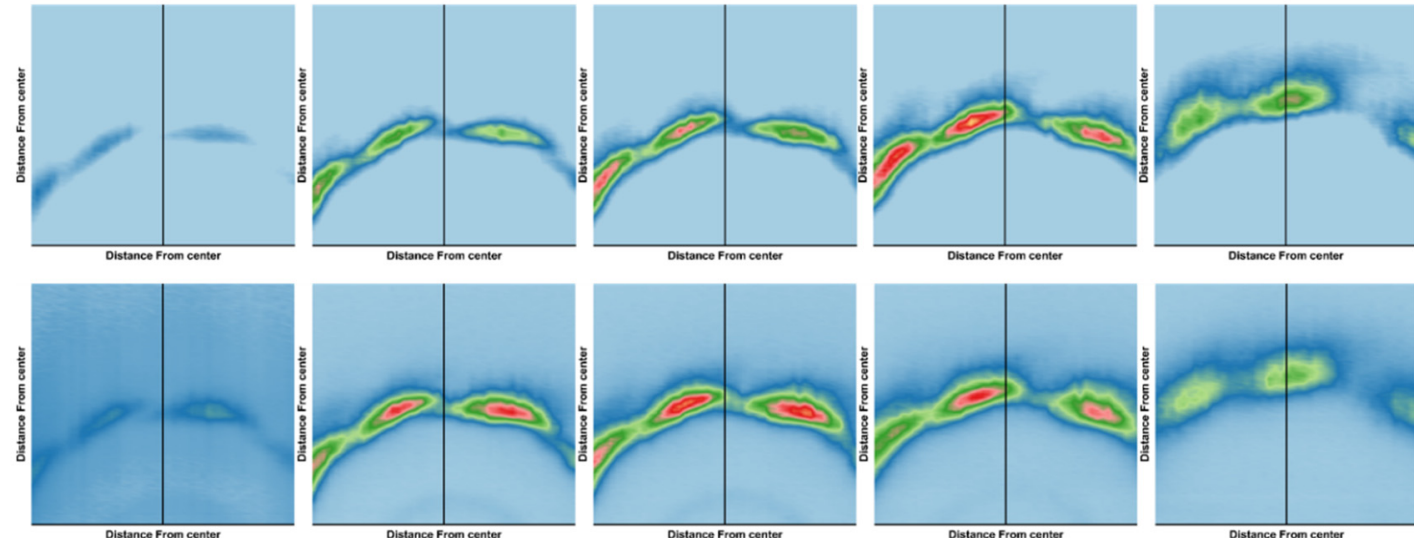

Figure 5.-Fuel pattern as revealed by fuel PLIF composites at five axial locations (columns) for three inlet conditions (rows). The distance from the dump plane increases from left to right.

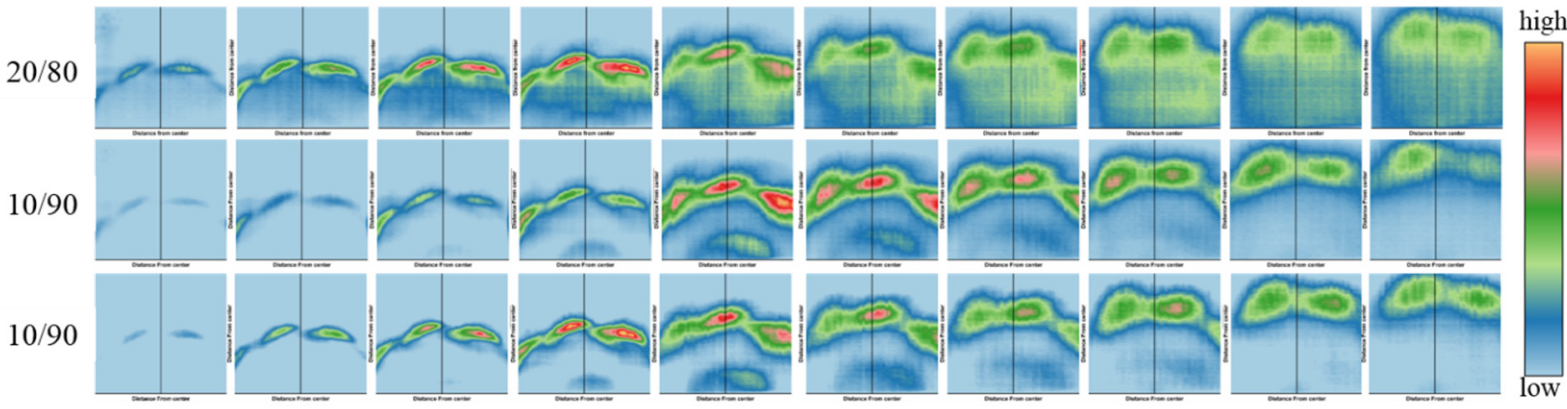

Figure 6.-End view composites of OH via PLIF. Each column shows an axial slice. Distance from dump plane increases from left to right. The first five columns correspond to the axial locations for fuel PLIF in Figure 5. 
Figure 7 shows chemiluminescence images from eight variations of inlet condition (rows), for species (columns, left to right) $\mathrm{CH}^{*}, \mathrm{C}_{2}{ }^{*}, \mathrm{OH}^{*}$, and $\mathrm{NO}^{*}$. Flow is left to right. Because the variation in signal was so great, each $\mathrm{C}_{2} *$ and $\mathrm{CH}^{*}$ image is individually scaled. $\mathrm{OH}^{*}$ and $\mathrm{NO}^{*}$ are scaled per specie. Each image is a line-of-sight average through the flow field rather than spatially-resolved as with PLIF.

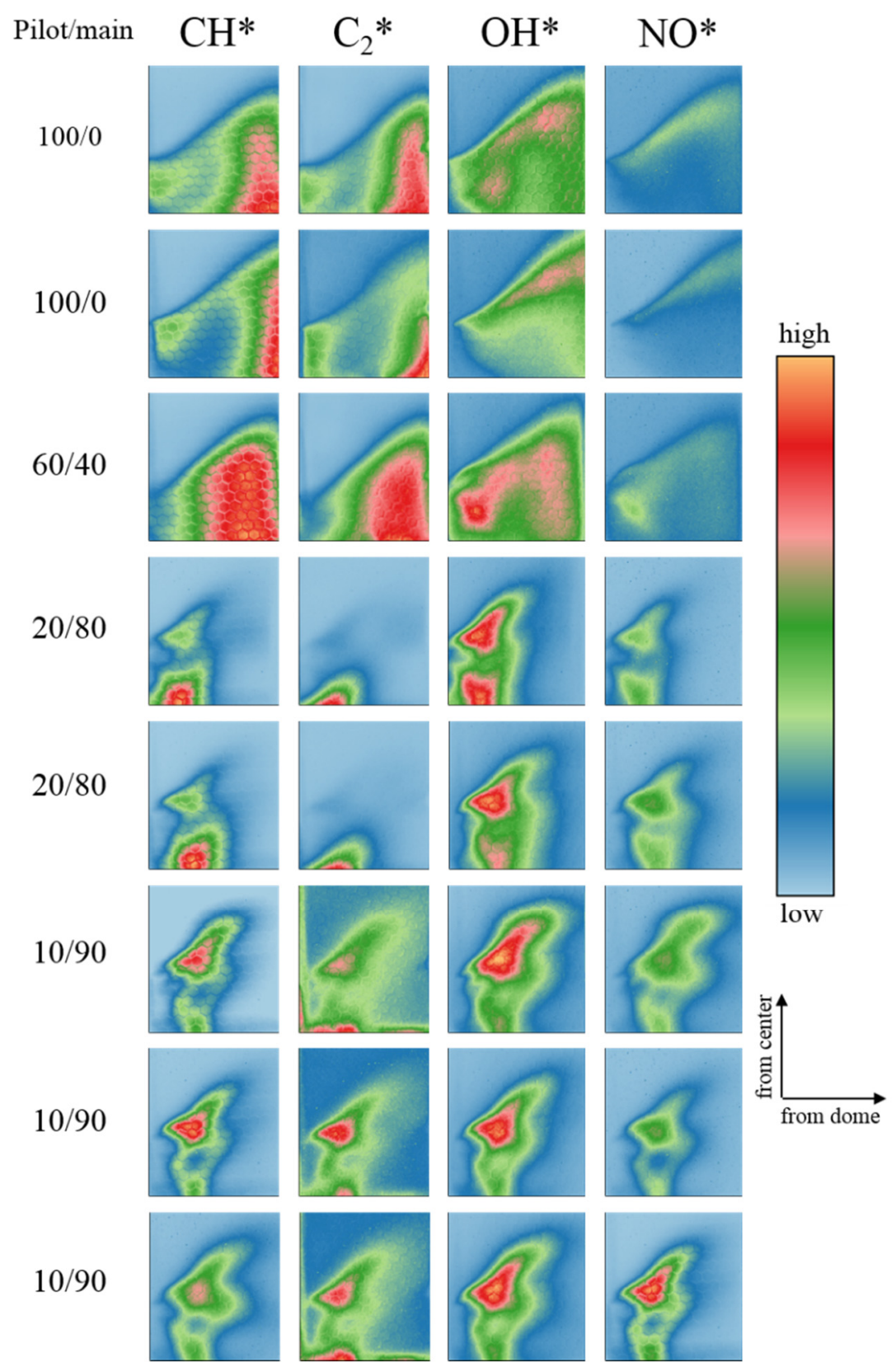

Figure 7.-Chemiluminescence images from eight variations of inlet condition (rows), for species (columns, left to right) $\mathrm{CH}^{*}, \mathrm{C}_{2}{ }^{*}, \mathrm{OH}^{*}$, and $\mathrm{NO}^{*}$. Flow is left to right. Images from $\mathrm{CH}^{*}$ and $\mathrm{C}_{2}{ }^{*}$ are independentlyscaled. Images for $\mathrm{OH}^{*}$ and $\mathrm{NO}^{*}$ are scaled for each species group. 
We note first that $\mathrm{NO}^{*}$ tends to track well with $\mathrm{OH}^{*}$ regardless of fuel split. This is reasonable because bulk $\left[\mathrm{OH}^{*}\right]$ follows flame temperature. Second, differences between $\mathrm{CH}^{*}$ and $\mathrm{C}_{2} *$ are best revealed when comparing the 20/80 and 10/90 fuel splits. Although for the 20/80 split, the signal from the main region is lower than the pilot for both species, $\mathrm{C}_{2} *$ main chemiluminescence is nearly absent. For the 10/90 split, pilot and main $\mathrm{C}_{2} *$ signals are of the same order, but $\mathrm{CH}^{*}$ signal is higher in the main than from the pilot region. Since $\mathrm{C}_{2}{ }^{*}$ intensity peaks at higher FAR than $\mathrm{CH}^{*}$, this may be a way to qualitatively differentiate between local differences in FAR. Also, for these conditions, $\mathrm{CH}^{*}$ tracks more with $\mathrm{OH}^{*}$; this volume is likely to indicate the main fuel/air mixing and burning zone.

We also note that the heavily-fueled pilot splits of $100 / 0$ and $60 / 40$ have much different flame structure compared to the 20/80 and 10/90 fuel split conditions, particularly between the predominantly fuel side species $\left(\mathrm{CH}^{*}, \mathrm{C}_{2}{ }^{*}\right)$ and the air side specie $\left(\mathrm{OH}^{*}\right)$. For the cases that have higher pilot fuel flow, the reactions persist through the full axial extent of the field of view and is consistent with a locally fuelrich system. We also saw quite high luminosity from $\mathrm{C}_{2}{ }^{*}$ and $\mathrm{CH}^{*}$, indicating lots of fuel breakdown occurring and possible soot formation. (The signal at these conditions far exceeded that from the 20/80 and 10/90 fuel split conditions, by roughly two orders of magnitude, which is why each image showing $\mathrm{C}_{2}{ }^{*}$ and $\mathrm{CH}^{*}$ is self-scaled.) Near the dump plane is a region of moderately high $\mathrm{C}_{2}{ }^{*}$ and $\mathrm{CH}^{*}$, but most of the heat release due to those species is downstream, near the end of the field-of-view. In the gap between those maxima is where $\mathrm{OH}^{*}$ forms, as well as along the air side of the reactant conical plume. NO* forms predominantly within that plume.

The 60/40 fuel split condition presented the highest levels of $\mathrm{C}_{2}{ }^{*}$ and $\mathrm{CH}^{*}$ chemiluminescence, approximately four times the signal level of the pilot-only cases. The 60/40 fuel split images (third row) reveal that the onset of chemiluminescence begins much closer to the dome than for the $100 / 0$ splits. We saw from the OH PLIF (Figure 4) a more filled in annular region between the pilot and main circuits, which supports the earlier onset of activity from $\mathrm{C}_{2}{ }^{*}$ and $\mathrm{CH}^{*}$ and higher signal levels observed.

Aside from the differences noted previously between $\mathrm{C}_{2}{ }^{*}$ and $\mathrm{CH}^{*}$, the 20/80 and 10/90 split cases reveal similar structure for all species, particularly near the mains.

Finally, we note the similarities between $\mathrm{OH}^{*}$ chemiluminescence and $\mathrm{OH}$ PLIF signals for the 100/0 and 60/40 split conditions (rows 1 and 3 of Figure 7; side views of Figure 3 and Figure 4).

\section{Velocity and Droplet Size Results_-Pilot Only Inlet Conditions}

For the TAPS injector, we expected to have two key recirculation zones, one downstream from the pilot circuit and another downstream of the main circuit. We wanted to determine the central recirculation zone (CRZ) size and the magnitude of reverse axial velocity. Given the optical access, we could not access the region near the centerline using our 2D PIV system. We therefore used the phase Doppler interferometer to explore the area near the TAPS centerline to obtain 3 velocity components and to measure droplet sizes. Our setup did not allow access to the dump plane region, where we might expect to see strong reverse flow. The results from the PDI, shown in Figure 8 and Figure 9, indicate that our measurement locations were likely just downstream of the CRZ because the magnitude of reverse flow was very small compared to the downstream velocity. Figure 8 shows the velocity field for the pilot only condition, point 1 , at two axial positions. The left image shows a contour of the axial velocity field, which features a central zone of lower velocity. As one moves outward from the center, the axial velocity increases, which is consistent with the zone of the conical fuel spray. The left image has an overlay of the horizontal-vertical (y-z) vectors and shows the core flow moves in a counterclockwise direction. Figure 9 provides some droplet statistics over the traverse range available for four axial positions. The plots include data from the most upstream to the farthest downstream locations that had enough droplets counted for good statistics. The histograms on the top row show that most droplets have a mean diameter of about $30 \mu \mathrm{m}$. The scatter plots indicate axial velocity as a function of linear droplet size, $\mathrm{D}_{10}$. Only a relative few droplets travel upstream, which is another indicator that the region probed is at the downstream edge of the CRZ. 


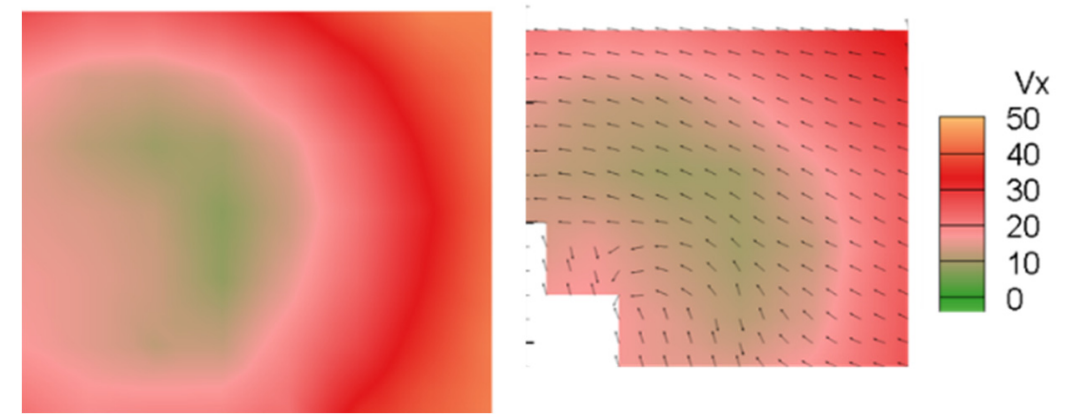

Figure 8.-PDI result, test point 1. Contours of average velocity field at two axial locations. Plot on right includes vectors representing the horizontal-vertical velocity components.
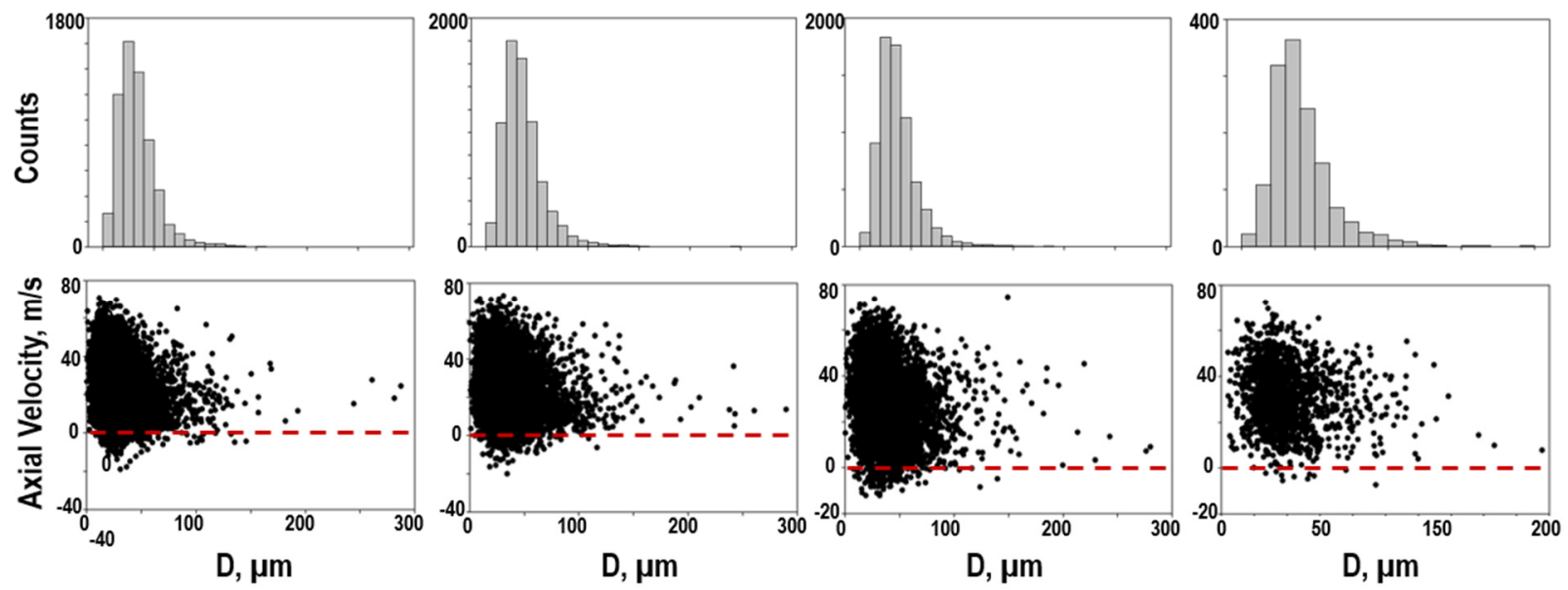

Figure 9.-PDI result, test point 1. Distribution of droplet size, D10, at four axial locations. Top row shows droplet size histograms. Bottom row shows distribution of droplet size with axial velocity.

The 2D velocity data were acquired using PIV. We used two setups. In the first, a pair of laser sheets was sent vertically through the top window (as with PLIF measurements), to obtain axial-vertical (X-Z) velocity components. In the second configuration, we used horizontal laser sheets and positioned the camera above the rig, to obtain axial-horizontal (X-Y) components. Figure 10 shows the axial-vertical velocity field for point 2 (pilot only) at a Y-position that corresponds to the position of the main, as shown in the inset fuel PLIF image (in grayscale). The key feature to highlight is the recirculation region near the dome and in the shear region between the pilot and main regions.

Figure 11 and Figure 12 are from test point 1 . They show axial-horizontal velocity components at the closest position to the centerline we could be, given the field of view, which is roughly a slice near the outer radius of the pilot region. Figure 11 features the fuel spray cone. Figure 12 shows a result using seeded air, in which can be seen near the bottom, a region of high downstream velocity. This region is probably due to the nitrogen purge through the main fuel circuit, used to help prevent fuel line coking. As was observed in the combusting system of Figure 10, one can also see a recirculation region between the main circuit and the pilot circuit in this unfueled case. 


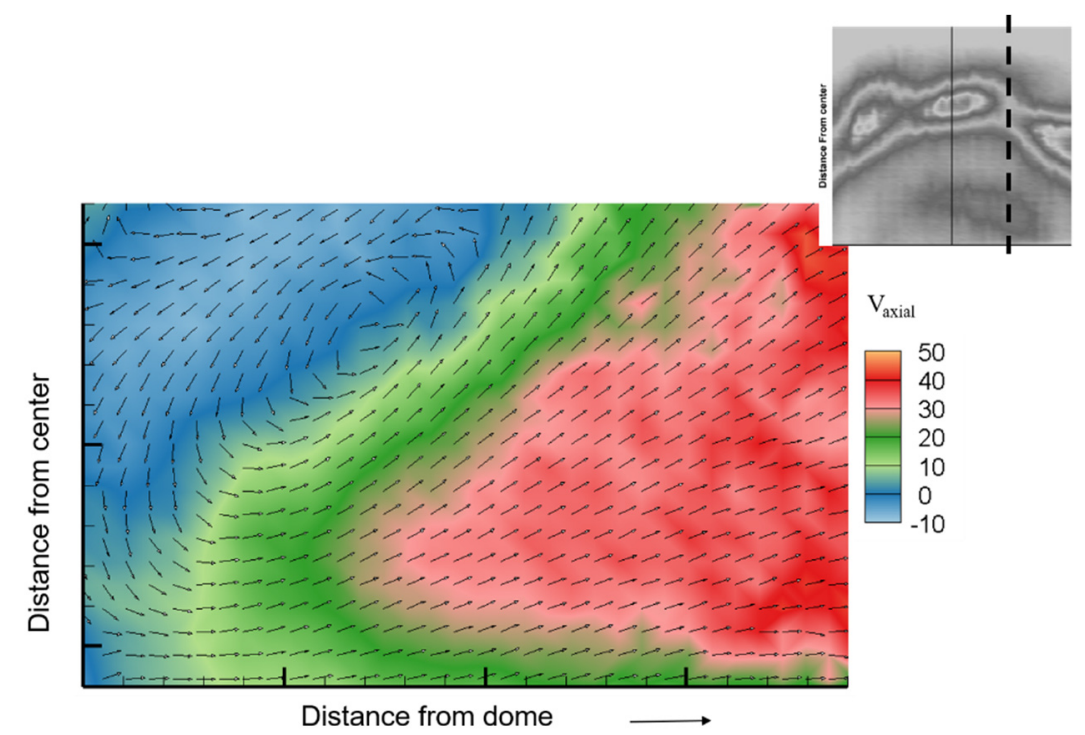

Figure 10.-PIV result. Average axial-vertical velocity field during combustion at pilot-only test point 2, in the Y-plane near the edge of a main injection site. Color contour is of axial velocity. The heavy dashed line in the inset (test point 5 fuel PLIF) shows the probed location for the velocity contour.

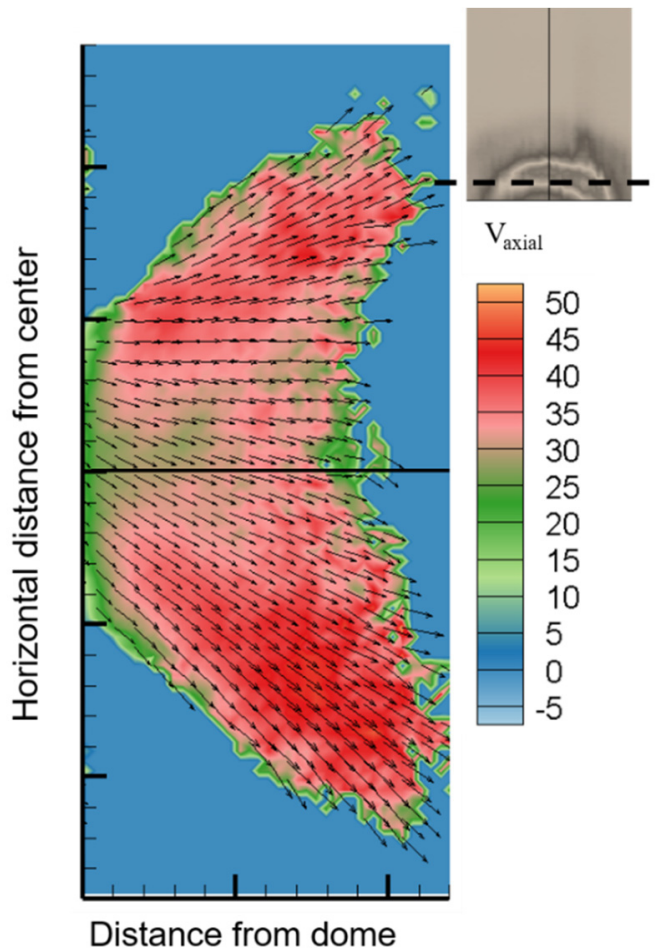

Figure 11.-PIV result. Average axial-horizontal velocity field of the fuel spray, in the region near the upper arc of the pilot for test point 1. Color contour is of axial velocity. The heavy dashed line in the inset (test point 1 fuel PLIF) shows the probed location for the velocity contour.

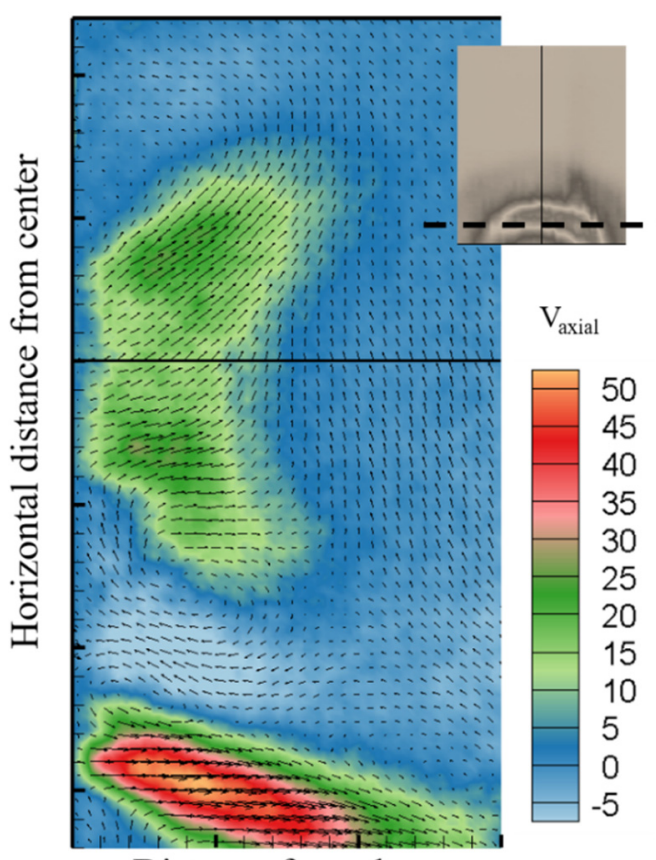

Distance from dome

Figure 12.-PIV result. Average axialhorizontal velocity field of the air, in the region near the upper arc of the pilot for test point 1 . Color contour is of axial velocity. The heavy dashed line in the inset (test point 1 fuel PLIF) shows the probed location for the velocity contour. 


\section{Spontaneous Raman Scattering Results-10/90 Split Inlet Conditions}

Figure 13 shows air spectra acquired under the inlet temperature and pressure conditions of point 5. The spectra were not calibrated for quantitative species concentration since the main focus was to determine flame temperature. Therefore, relative speciation was sufficient. Each plot is from one of seven spectra (rows 3-9 in the 2-D Raman image) used for analysis. The Raman images were processed to remove noise spikes and smoothed using a Lee filter. Only rows 3-9 were used here because the signal-tonoise ratio in rows 0,1 and 2 was low (with respect to speciation). As expected, two peaks are evident from $\mathrm{O}_{2}$ at a Raman shift of $1556 \mathrm{~cm}^{-1}$ and $\mathrm{N}_{2}$ at a Raman shift of $2331 \mathrm{~cm}^{-1}$. We also show on the graph the locations of typical peaks that might appear during combustion: $\mathrm{CO}_{2}$ at $1285 \mathrm{~cm}^{-1}$ and $1388 \mathrm{~cm}^{-1}$. Figure 14 shows an example of spectra acquired in burning tests for a 10/90 split condition. The convolved $\mathrm{CO}_{2}$ peaks are present, but there is no evidence of $\mathrm{CO}$ (which probably signifies complete combustion).

The rest of this section focuses on the Stokes and anti-Stokes lines in the spontaneous vibrational Raman spectra of $\mathrm{N}_{2}$, which may be used to shed light on the temperature at points throughout the probed flow path. Specifically the ratio of the area under the anti-Stokes $\mathrm{N}_{2}$ peak over the area under the Stokes $\mathrm{N}_{2}$ peak was calculated to estimate the temperature for a few test conditions. All ten rows were used to derive temperatures. Given our results, we think this technique works well in this combusting environment.

Figure 15 shows an example of a Raman temperature map, with the locations probed shown spatially in relation to a center plane slice of OH PLIF. Although much of the Raman signal acquired during these tests did not explicitly probe the pilot or main flame, the probe area does give a sense of pilot and main interaction. For the temperatures, we used all ten rows, calibrating each row and axial location separately in air at several temperatures, to generate calibration curves of Anti-Stokes/Stokes ratio versus temperature using a method such as described in References 15 and 16. The OH PLIF image shows the primary flame zone where the hottest flame temperatures are expected. In Figure 15 there are two distinct regions: the bottom region where the bulk of the OH PLIF signal originates from the pilot and the upper region where we observe a larger signal spreading through the image from the main.

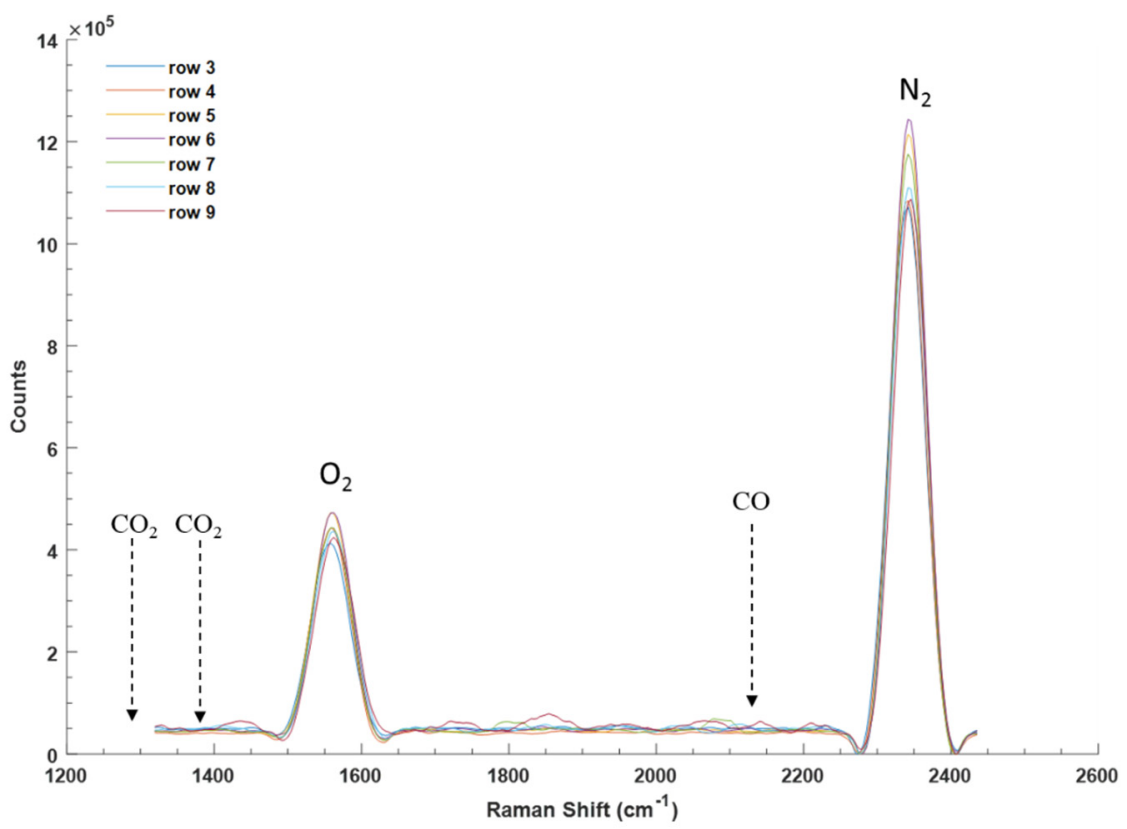

Figure 13.-Sample spectra from air at $\mathrm{T}_{3}=770^{\circ} \mathrm{F}$ and $\mathrm{P}_{3}=250$ psia (unfueled). Multiple spectra corresponding to each binned row of the fiber optic are shown. 


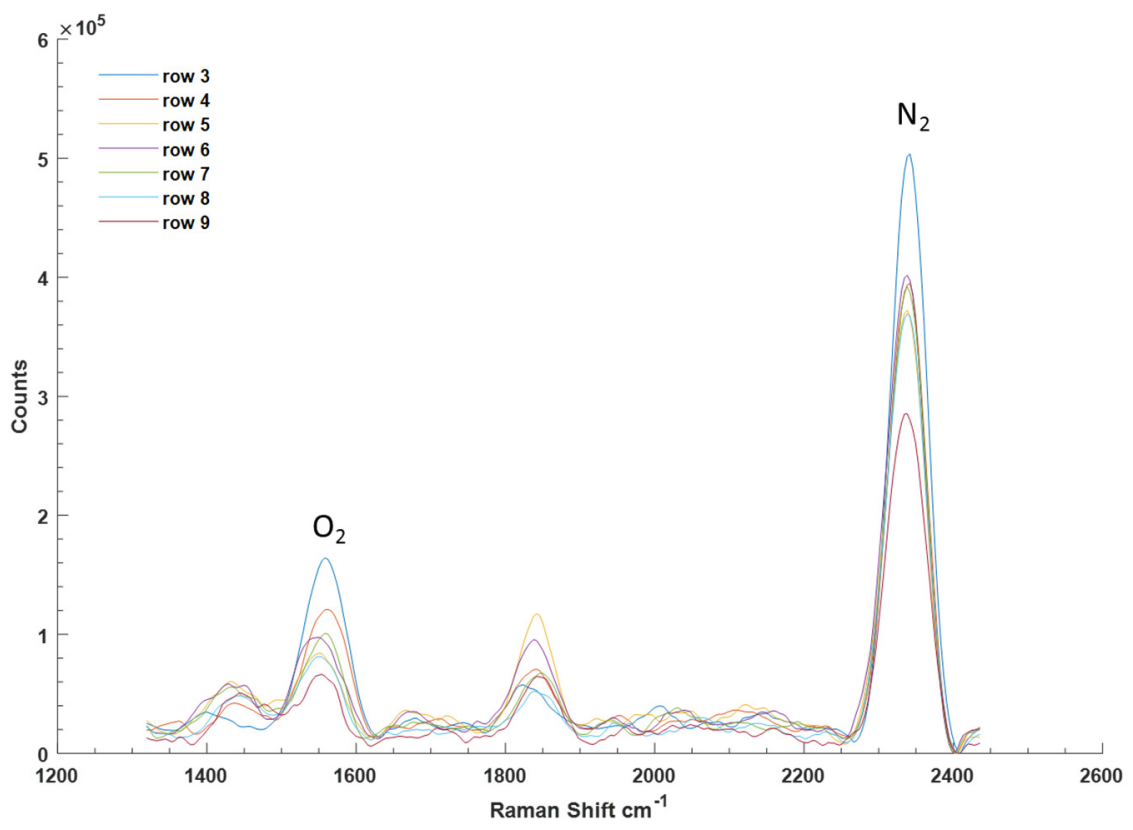

Figure 14.-Sample spectra from a particular 10/90 split condition at position $\mathrm{x}=0 . \mathrm{T}_{3}=1000^{\circ} \mathrm{F}$ and $\mathrm{P}_{3}=250$ psia. Multiple spectra corresponding to each binned row of the fiber optic are shown.

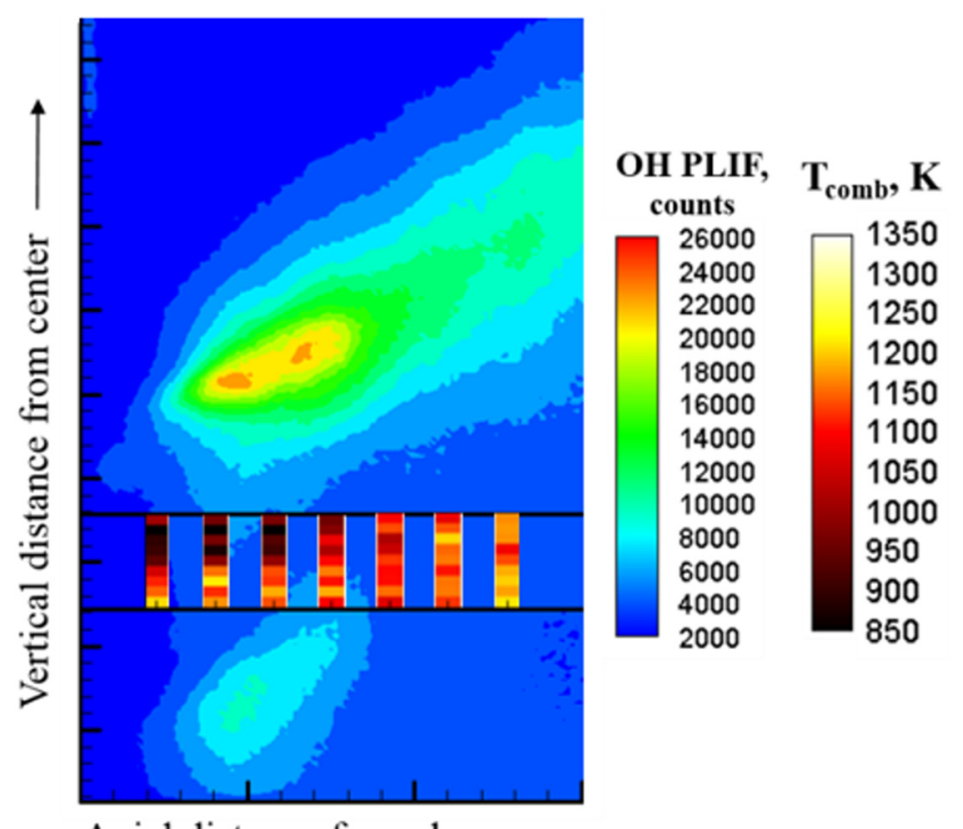

Axial distance from dome $\longrightarrow$

Figure 15.-OH PLIF for a particular 10/90 split condition. Overlaid boxes display the Raman temperature data and probed locations. $\mathrm{T}_{3}=1000^{\circ} \mathrm{F}$ and $\mathrm{P}_{3}=250$ psia. 


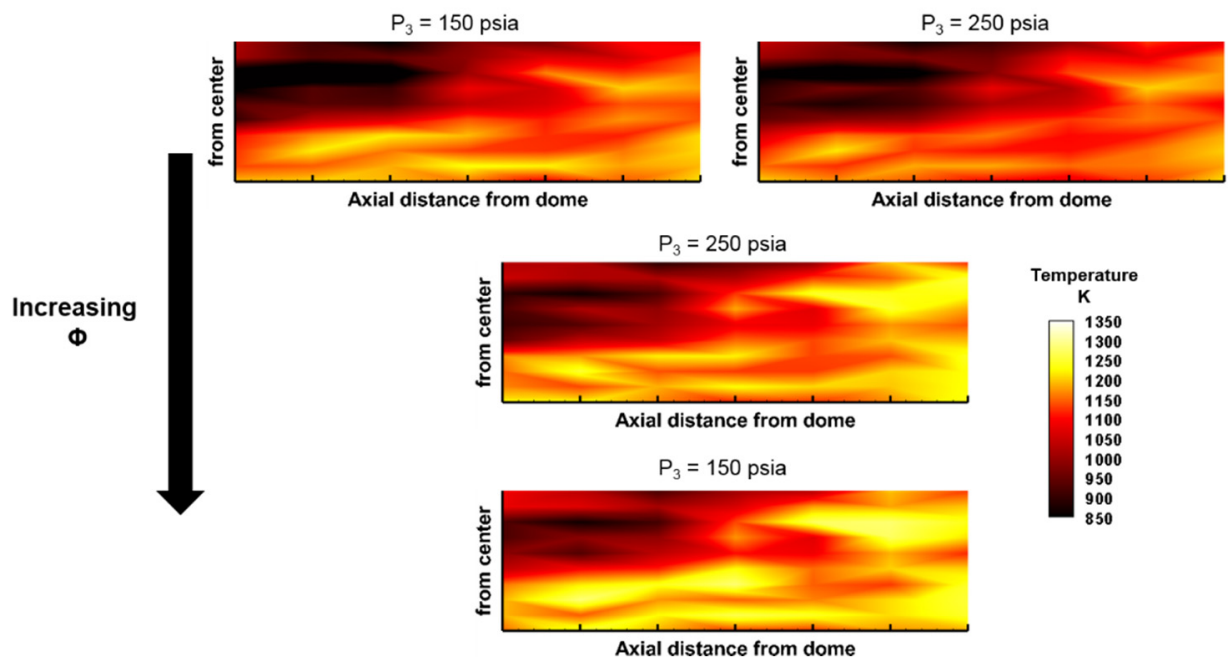

Figure 16.-Temperature maps created by taking ratio of the area under the anti-Stokes $\mathrm{N}_{2}$ line over the area under the Stokes $\mathrm{N}_{2}$ line. The inlet temperature was nominally $1000^{\circ} \mathrm{F}(811 \mathrm{~K})$ in all cases.

Qualitative temperature maps at four 10/90 split conditions are shown in Figure 16, and the top right image of Figure 16 corresponds to the inlet conditions from the PLIF image in Figure 15. In these images, we interpolated in the axial direction because we think it is easier to visualize the trends. One can observe some resemblance between the OH PLIF in Figure 15 and the temperature map. Weak OH PLIF was measured in the upstream section of the probe area, and slightly stronger OH PLIF was measured in the outer radial and downstream sections. This trend is also observed in the corresponding temperature map shown in the top right image of Figure 16. Calculated temperatures from the Raman data showed a pocket of cooler air at an axial location closer to the dome. Also, similar to the OH PLIF image, the temperature maps show higher temperatures at the downstream locations of the probed area.

The four 10/90 split conditions shown in Figure 16 are plotted on the same scale. The inlet temperature in all cases was $1000^{\circ} \mathrm{F}(811 \mathrm{~K})$. Equivalence ratio increases from top to bottom. The effect of increasing $\phi$ is apparent in that increasing the equivalence ratio increased temperature considerably. This effect makes sense as higher equivalence ratios for overall fuel-lean mixtures lead to hotter flames. The top row shows results for conditions with the same overall equivalence ratio, but at different pressures. $\mathrm{P}_{3}$ was 150 psia for the left image, and $\mathrm{P}_{3}$ was 250 psia for the right image. One might expect the same flame temperatures for conditions with the same equivalence ratio and inlet temperature. The lower pressure condition shows a slightly higher temperature of about 10 degrees Kelvin, but this is within the measurement error.

\section{Conclusion}

An investigation into the performance in an optically accesible flame tube facility of a GE TAPS injector is reported in this paper. Several optical and laser-based techniques were used to visualize the injector flow field. The effort aimed to examine the effect of fuel staging on fuel spray drop size, patternation and flame structure in the reaction zone under several different inlet conditions.

Fuel PLIF images showed near symmetric distribution about the center of the injector. In particular, the fuel split conditions of 20/80 (pilot/main) and 10/90 had very similar fuel patternation and appeared more evenly distributed compared to the $60 / 40$ condition. In terms of the OH PLIF, the $60 / 40$ fuel split condition indicated a bimodal axial distribution with most of the signal located outside the fuel PLIF location. OH PLIF in the 20/80 split case showed more even distribution compared to the 10/90 split. The 10/90 split cases, in particular, showed little $\mathrm{OH}$ within the inner cone. 
From the chemiluminescence images, we saw that $\mathrm{NO}^{*}$ tracked reasonably well within $\mathrm{OH}^{*}$ between all fuel split conditions. A substantial difference in the flame structure was observed from the $100 / 0$ and $60 / 40$ splits versus the $20 / 80$ and $10 / 90$ splits. The high pilot flow conditions revealed flame reactions extending the full axial extent of the field of view, which is consistent with fuel-rich flames. In addition, the higher pilot flow conditions showed moderately high concentrations of $\mathrm{C}_{2}{ }^{*}$ and $\mathrm{CH}^{*}$ near the dump plane; these species also peak at the trailing edge of the field of view. Between these areas of peak concentrations, $\mathrm{OH}^{*}$ formation was highest. It is noteworthy that the $\mathrm{NO}^{*}$ also peaked within this $\mathrm{OH}^{*}$ region.

PDI measurements probed a location near the TAPS centerline. The PDI setup did not allow access to the dump plane, which is where strong reverse flow might be expected. From the PDI results, there was a central zone of lower velocity which increased outward from the center, which is consistent with conical fuel sprays. Drop size distributions at locations upstream and further downstream showed most drops had a mean diameter of about $50 \mathrm{um}$. Axial velocities of several drop sizes also showed that relatively few droplets travel upstream, indicative of a region probed downstream of the CRZ. Axial-vertical and axialhorizontal slices from the PIV results indicated that a recirculation zone was present. In particular, we observed a recirculation region near the dome within a shear layer between the pilot and mains.

Temperature maps were created from the spontaneous Raman spectra for four of the 10/90 split conditions. These were done by taking the ratio of the area under the anti-Stokes $\mathrm{N}_{2}$ peak over the area under the Stokes $\mathrm{N}_{2}$ peak. From these results, we observe an increase in temperature with increasing equivalence ratio. Based on these results, the Stokes-Anti-Stokes ratio technique for temperature measurement seems feasible for use in future work.

\section{References}

1. Lee, D.S., Pitari, G., Grewe, V., Gierens, K., Penner, J.E., Petzold, A., Prather, M.J., Schumann, U., Bais, A., Berntsen, T., Iachetti, D., Lim, L.L., and Sausen, R., Atmospheric Environment, Vol. 44, 2010, pp. 4678-4734.

2. Mongia, H.C., "TAPS-A $4^{\text {th }}$ Generation Propulsion Combustor Technology for Low Emissions," Paper AIAA-2003-2657, 2003.

3. Bulzan, D., "Supersonics Project High Altitude Emissions Overview," 2012 Fundamental Aeronautics Program Technical Conference, 2012.

4. Lee, C.-M., Chang, C., Kramer, S., and Herbon, J.T., "NASA Project Develops Next Generation Low-Emissions Combustor Technologies," Paper AIAA-2013-0540, 2013.

5. Foust, M.J., Thomsen, D., Stickles, R. Cooper, C. and Dodds, W., "Development of the GE Aviation Low Emissions TAPS Combustor for Next Generation Aircraft Engines," Paper AIAA-2012-0936, 2012.

6. Stickles, R. and Barrett, J., “TAPS II Combustor Final Report-Technology Assessment Open Report," FAA Continuous Lower Energy, Emissions and Noise (CLEEN) Program, Report number DOT/FAA/AEE/2014-03, 2014.

7. Kojima, J., Ikeda, Y., and Nakajima, T., "Basic aspects of $\mathrm{OH}(\mathrm{A}), \mathrm{CH}(\mathrm{A})$, and $\mathrm{C} 2(\mathrm{~d})$ chemiluminescence in the reaction zone of laminar methane-air premixed flames," Combustion and Flame, vol. 140, 2005, pp. 34-45.

8. Nori, V. and Seitzman, J., "Evaluation of Chemiluminescence as a Combustion Diagnostic under Varying Operating Conditions," Paper AIAA-2008-953, 2008.

9. Guyot, D. et al., $\mathrm{CH}^{*} / \mathrm{OH}^{*}$ Chemiluminescence Response of an Atmospheric Premixed Flame under Varying Operating Conditions, GT2010-23135, 2010.

10. Guiberti, T.F., Durox, D., and Schuller, T., "Flame Chemiluminescence from CO2- and N2-diluted laminar CH4/air premixed flames," Combustion and Flame, vol. 181, 2017, pp. 110-122.

11. Baranger, P., Orain, M., and Grisch, F., "Fluorescence Spectroscopy of Kerosene Vapour: Application to Gas Turbines," Paper AIAA-2005-828, 2005. 
12. Hicks, Y.R., Locke, R.J., Anderson, R.C., Zaller, M., and Schock, H.J., "Imaging Fluorescent Combustion Species in Gas Turbine Flame Tubes: On Complexities in Real Systems," Paper AIAA 97-2837, 1997.

13. Friedel, R.A., and Orchin, M., Ultraviolet Spectra of Aromatic Compounds, Wiley \& Sons, New York, 1951, pp. 12-14.

14. Berlman, I.B., Handbook of Fluorescence Spectra of Aromatic Molecules, $2^{\text {nd }}$ ed., Academic Press, New York, 1971, Chaps. 3-4, pp. 114-115, 330.

15. Rabenstein, F. and Leipertz, A., "Two-dimensional temperature determination in the exhaust region of a laminar flat-flame burner with linear Raman scattering," Applied Optics, vol. 36, no. 27, 1997, pp. 6989-6996.

16. Lederman, S., "The use of laser Raman diagnostics in flow fields and combustion," Prog.EnergyCombust.Sci., vol. 3, 1977, pp. 1-34. 


